\title{
Application of Behavior Management Techniques for Paediatric Dental Patients by Tanzanian Dental Practitioners
}

\author{
Hassan Mohamed Kawia, Hawa Shariff Mbawalla, Febronia Kokulengya Kahabuka*
}

Department of Orthodontics, Paedodontics and Preventive Dentistry, School of Dentistry, Muhimbili University of Health and Allied Sciences, P.O. Box 65014, Dar es Salaam, Tanzania

\begin{abstract}
Background: Management of children's behavior is an integral component of pediatric dental practice. Objective: To investigate the oral health care providers' awareness, use and factors for choice of behavior management techniques when attending paediatric dental patients. Methods: A cross-sectional study among dental practitioners in Dar es Salaam, Tanzania. Data collection was done through interview using a structured questionnaire. The recorded information included: awareness and application of behavior management techniques (BMT) when attending a child dental patient, factors influencing choice of a particular technique, socio-demographics, level of professional training, working experience and facility profile. Using SPSS program version 18, frequency distributions and cross tabulations analyses were performed. Results: 74 dental practitioners participated in the study, of whom $49(66.2 \%)$ were males and 44 $(59.5 \%)$ were graduates. Most participants were aware of the behavior management techniques, ranging from $100 \%$ for Tell-Show-Do to $86 \%$ for distraction. A small proportion (9.5\%) reported to have adequate skills, all of them were graduates. The use of universally accepted BMTs was reported by $65 \%$ of experienced practitioners, $61 \%$ of graduates, $59 \%$ of those reporting to have received formal training and all of those reporting to have fair/inadequate skills to apply BMTs $(\mathrm{p}=0.01)$. Conclusion: Most participants were aware of BMTs, although few acknowledged having adequate skills to apply the techniques. They use BMTs during treatment of paediatric dental patients and their choice of the technique is mainly influenced by children's factors.
\end{abstract}

Keywords: Awareness, behavior management techniques, paediatric, practitioners, professional training, Tanzania.

\section{INTRODUCTION}

Management of children's behavior is an integral component of pediatric dental practice [1]. It is as fundamental to the successful treatment of children as are hand piece skills and knowledge of dental materials in dental practice [2] and it is achieved through application of various Behavior Management Techniques (BMTs). BMTs are a set of procedures aimed at enhancing the child's useful coping skills, achieve complete willing and acceptance of dental care, and ultimately reduce the child's perception that the dental situation is overwhelming or dangerous [1]. In other words, the techniques are employed by dental practitioners in attending a child dental patient so as to establish communication, alleviate fear and anxiety, facilitate delivery of quality dental care, build a trusting relationship between dentist, child, and parent, and promote the child's positive attitude towards oral/ dental health and oral health care thus cope with and be willing to undertake dental treatment procedures [3-5].

Approaches for behavioural management changed considerably during the second half of the $20^{\text {th }}$ century, with an increasing emphasis on communication and empathic skills [6]. They have been codified into professionally derived

*Address correspondence to this author at the Muhimbili University of Health and Allied Sciences, United Nations Road, School of Dentistry, Department of Orthodontics, Paedodontics and Preventive Dentistry, $3^{\text {rd }}$ Floor Room 303, P.O. Box 65014, Dar es Salaam, Tanzania; Tel: +255-22-2151135; Fax: +255-22-2150465;

E-mails:kokukahabuka@yahoo.com, fkahabuka@muhas.ac.tz guidelines [7]. To date, a wide variety of behavior management techniques are available to dental practitioners $[8,9]$, namely; tell-show-do, desensitization, modeling, positive reinforcement, voice control, distraction, parental presence/absence, restrain/protective stabilization, non verbal communication, hand-over-mouth, sedation and general anaesthesia.

Behavior management techniques have been classified as pharmacological as opposed to non pharmacological, communicative (communication and communicative guidance) versus advanced behavior guidance techniques and universally accepted against non-universally accepted ones, as well as informal and common sense techniques versus formal relaxation techniques $[1,10]$. The classification into universally and non-universally applied techniques was used during analysis and reporting in this article.

Different authors have reported application of BMTs in different countries/societies. In the United States, Carr and Wilson [8] reported that the Southeastern US dentists used less aversive techniques and reported a marked reduction in the use of the hand over mouth exercise. A survey among active members of the American Academy of Pediatric Dentistry residing in the U.S. and Canada showed that only a minority used hand-over-mouth and active immobilization of sedated patients. No significant differences by groups were seen in respect to the use of most basic behavior management techniques. Significant differences by sex and age were seen for the use of non-verbal communication and advanced 
techniques. Most favored parental presence in the operatory, though older males were significantly less likely to allow parental presence for some procedures [11].

In Israel, Peretz et al. [12] showed that dentists used tellshow-do and material reinforcement more than any other behavior management strategies. Whereas in Australia, the most common strategies used were; permitting the child to exercise some form of control over terminating the treatment if they were experiencing difficulties, furnishing waiting areas with play materials, and using a tell-show-do approach. Few of the Australian dentists used hand-over-mouth technique [13]. Members of the Australian Society of Dentistry for Children differed from general dentists by more frequently teaching anxious children a technique of relaxation. Younger dentists tended to use behavioral strategies more frequently than older practitioners. Women dentists more frequently than male dentists used strategies including: spending more time with the child before entering the operatory; setting shorter appointment sessions; and permitting the child to hold a toy or a mirror during dental treatment [13].

Sharath et al. [14] and Grewal [15] in India showed that; Tell-Show-Do was the most common behavior management technique used and more aversive management techniques were rarely used in managing children in the dental office. In addition, Grewal [15] reported that $93 \%$ of the respondents used normal conversation technique and $30 \%$ had increased the use of behavior modification techniques. In Nigeria, the most frequently used behavior management techniques are; Tell-Show-Do followed by positive reinforcements, modeling, desensitization, restraints, sedation and hand over mouth [9].

Application of BMTs requires skills in communication, empathy, coaching, tolerance, flexibility, and active listening. As such, behavior guidance is a clinical art form and a skill built on a foundation of science [5]. Thus, dental practitioners are expected to be aware of behavior management techniques which will facilitate application of the techniques during routine handling of child dental patients. Furthermore, they are encouraged to utilize behavior guidance techniques consistent with their level of professional education and clinical experience. Since children exhibit a broad range of physical, intellectual, emotional, and social development and a diversity of attitudes and temperament, it is important that dentists have a wide range of behavior guidance techniques to meet the needs of the individual child and be tolerant and flexible in their implementation [13]. By virtue of differences in each clinician's training, experience, and personality, behavior guidance approach for a child may vary among practitioners.

No publications reporting awareness or application of behavior management techniques in Tanzania were retrieved despite its importance in creating positive attitude towards dentistry which should best begin during early childhood, subsequently creating a child's healthy oral environment and a future healthy adult. Therefore, the objective of the study was to investigate dental practitioners' awareness, use and factors for choice of behavior management techniques in attending paediatric dental patients in Dar es Salaam, Tanzania.

\section{MATERIALS AND METHODS}

A cross-sectional study was performed among oral health care providers working in Dar es Salaam city. The city was purposively selected to ensure availability of adequate number of participants. Dar es Salaam is Tanzania's business capital. It harbours the only dental school, assistant dental officers' school, the national hospital and a wide range of private dental facilities consequently majority of Tanzanian practicing dentists in both, public and private sectors are stationed in this city.

A list of all dental facilities (79) was obtained from respective authorities. Using the dental clinic as a sampling unit; a stratified simple one stage cluster sampling design was employed to select participating facilities. One third of all registered and practicing dental clinics placed at hospitals (6), health centers (5) and dispensaries (14) were randomly selected to take part in the study. Ultimately giving a total of 25 facilities, only 21 facilities participated, a response rate of $84 \%$. At the facilities (dental clinics) all working oral health care providers (dental specialists, dentists, assistant dental officers and dental therapists) were invited to participate. All intended participants were recruited either at first visit or follow-up/appointment visit.

A structured English questionnaire specifically designed for the purpose of this study was used to collect information through interview. The interview was conducted at the respective dental clinics by one of the authors (HMK). The questionnaire was pilot tested before the actual study commenced. It included questions that inquired on participants' socio-demographic characteristics, level of training, year of graduation, working experience, awareness on various BMTs, self-reported skills and their application. Other information included facility profile, the location of the facility and level of health facility where the dental clinic is placed.

Data entry, processing and analysis were done using a Statistical Package for Social Sciences (SPSS) computer program version 18. Sex was inquired and recorded as male or female, age in year groups of younger than 30, 30-39, 4049 , or 50 years and above. Information on facility profile inquired on; the location of the facility as urban, peri-urban or rural. Level of health facility where the dental clinic was placed to, was recorded as dispensary, health centre or hospital whereas the type of practice was scored as public, private or military. The oral health care providers' level of professional training was recorded as Dental Therapist, Assistant Dental Officer or Bachelor of Dental Science (BDS)/Doctor of Dental Surgery (DDS)/Specialist.

During analysis age was dichotomized into younger practitioners (below forty years) and older practitioners (forty years and above). Facilities were categorized as urban and rural, public and private as well as hospital and health centre/dispensary. The oral health care providers' level of training and working experience was categorized into graduates (BDS, DDS and Specialist) and non-graduate (Dental Therapists, Assistant Dental Officers) and experienced (worked for ten years or more) and less experienced (worked for less than ten years), respectively.

Behavior management techniques were grouped into universally applied and non-universally applied modified from 
Roberts et al. [1]. The universally applied BMTs included; tell-show-do, desensitization, non-verbal communication, positive reinforcement, modeling and distraction. The nonuniversally applied techniques included; parental presence/absence, voice control, hand over mouth, passive or active restraining and sedation. Regarding awareness, those who reported to know all the universally applied BMTs were considered as being aware and their counterparts not aware. Those who reported to use more than five of the seven universally applied BMTs in their daily practice were considered as users while those reporting infrequent use of the universally applied BMTs were considered non users.

Frequency distributions and cross tabulations analyses were performed. Chi-square test was used to test for statistical significant associations between dependent (awareness, self-reported skills and use of BMTs) and independent variables (socio-demographics, facility characteristics, level of professional training, working experiences). The level of statistical significance was determined at $p<0.05$.

\section{RESULTS}

A total of 74 dental practitioners participated in the study, of whom $49(66.2 \%)$ were males. Fifty six $(75.6 \%)$ were aged 40 years or younger, $68(92 \%)$ were working in urban located facilities, mainly at hospitals $51(69 \%)$ and at public facilities $53(72 \%)$. Forty four participants $(60 \%)$ were graduates (BDS, DDS and Specialist). Large proportions had worked for less than ten years $57(77 \%)$, reported to have received formal training on BMT $46(62 \%)$, had fair or inadequate skills on BMT $67(90 \%)$, were aware of 55 (74\%) and used the universally accepted behavior management techniques $41(55 \%)$ in their practice (Table 1).

Frequency distribution of practitioners' awareness on behavior management techniques is presented in (Table 2). Most participants were aware of 10 out of 11 studied behavior management techniques. All participants were aware of tell-show-do while a few $22(29.7 \%)$ were aware of hand over mouth technique

Awareness of the universally accepted techniques was reported mostly by younger practitioners $42(75 \%)$, males 37 (77\%), those working at hospitals $51(78.4 \%)$ and at public facilities 41 (77\%), (Table 3). Similarly, larger proportions reporting to use the universally applied techniques were; 11 (61\%) older practitioners, $28(58 \%)$ males, $29(56.9 \%)$ those practicing at hospitals and $12(57.1 \%)$ at private facilities, (Table 4). However, the differences in awareness and use of BMTs with these socio demographics and profile characteristics were not statistically significant.

The practitioners' awareness on universally applied behavior management techniques by experiences and training is presented in (Table 5). Three quarters $43(75.4 \%)$ of the less experienced practitioners, $41(93 \%)$ graduates $(p=0.001), 41$ $(89 \%)$ of those who received formal training $(p=0.001)$, and all of those $7(100 \%)$ reporting to have fair/inadequate skills were aware of universally accepted BMTs. The studied practitioners' use of universally accepted BMTs is presented in (Table 6). It was reported by $11(64.7 \%)$ of experienced practitioners, 27 (61.4\%) of graduates, 27 (58.7\%) of those reporting to have received formal training and all of those reporting to have fair/inadequate skills to apply BMTs $(p=0.01)$.
Table 1. Sample profile.

\begin{tabular}{|c|c|c|}
\hline \multicolumn{2}{|c|}{ Variable and its categories } & \multirow{2}{*}{$\begin{array}{c}\%(n) \\
75.6(56)\end{array}$} \\
\hline Aos of nonticinonts & Younger dentists & \\
\hline & Older dentists & $24.4(18)$ \\
\hline \multirow{2}{*}{ Location of the Facility } & Urban & $91.9(68)$ \\
\hline & Rural & $8.1(6)$ \\
\hline \multirow{2}{*}{ Level of facility } & Dispensary/Health Centre & $31.1(23)$ \\
\hline & Hospital & $68.9(51)$ \\
\hline \multirow{2}{*}{ Type of practice } & Public & $71.6(53)$ \\
\hline & Private & $28.4(21)$ \\
\hline \multirow{2}{*}{$\begin{array}{l}\text { Level of professional } \\
\text { training }\end{array}$} & Non graduate & $40.5(30)$ \\
\hline & Graduate & $59.5(44)$ \\
\hline \multirow{2}{*}{ Working experience (years) } & Less experienced & $77.0(57)$ \\
\hline & Experienced & $23.0(17)$ \\
\hline \multirow{2}{*}{$\begin{array}{l}\text { Received Formal training } \\
\text { on BMT }\end{array}$} & Yes & $62.2(46)$ \\
\hline & No & $37.8(28)$ \\
\hline \multirow{2}{*}{ Self-reported skill on BMT } & Adequate & $9.5(7)$ \\
\hline & Fair/inadequate & $90.5(67)$ \\
\hline \multirow{2}{*}{$\begin{array}{l}\text { Aware of universally } \\
\text { accepted BMT }\end{array}$} & Aware & $74.3(55)$ \\
\hline & Not aware & $25.7(19)$ \\
\hline \multirow{2}{*}{$\begin{array}{l}\text { Use of universally accepted } \\
\text { BMT }\end{array}$} & Use & $55.4(41)$ \\
\hline & Do not use & $44.6(33)$ \\
\hline
\end{tabular}

Table 2. Frequency distribution of practitioners' awareness on behavior management techniques.

\begin{tabular}{|c|c|}
\hline Technique & \% (n) \\
\hline \hline Tell show do & $100(74)$ \\
\hline Restrain / protective stabilization & $98.6(73)$ \\
\hline Parental presence or absence & $95.9(71)$ \\
\hline Sedation & $95.9(71)$ \\
\hline Desensitization & $94.6(70)$ \\
\hline Voice control & $93.2(69)$ \\
\hline Non verbal communication & $91.9(68)$ \\
\hline Positive reinforcement & $91.9(68)$ \\
\hline Modeling & $90.5(67)$ \\
\hline Distraction & $86.5(64)$ \\
\hline Hand over mouth & $29.7(22)$ \\
\hline
\end{tabular}


Table 3. Distribution of practitioner's awareness of universally applied behavior management techniques by participants' demographics and facility characteristics.

\begin{tabular}{|c|c|c|c|c|}
\hline & & $\begin{array}{l}\text { Aware of universally accepted } \\
\text { BMT \% (n) }\end{array}$ & $\begin{array}{c}\text { Not aware of universally accepted } \\
\text { BMT \% (n) }\end{array}$ & P-value \\
\hline \multirow{2}{*}{ Age } & Younger dentists & $75.0(42)$ & $25.0(14)$ & \\
\hline & Older dentists & $72.2(13)$ & $27.8(5)$ & 0.814 \\
\hline Sex & Male & $77.1(37)$ & $22.9(11)$ & \\
\hline \multirow{2}{*}{ Level of facility } & Dispensary & $65.2(15)$ & $34.8(8)$ & \\
\hline & Hospital & $78.4(51)$ & $21.6(11)$ & 0.228 \\
\hline \multirow{2}{*}{ Type of practice } & Private & $66.7(14)$ & $33.3(7)$ & \\
\hline & Public & $77.4(41)$ & $22.6(12)$ & 0.343 \\
\hline
\end{tabular}

Table 4. Distribution of practitioner's use of on universally applied behavior management techniques by participants' demographics and facility characteristics.

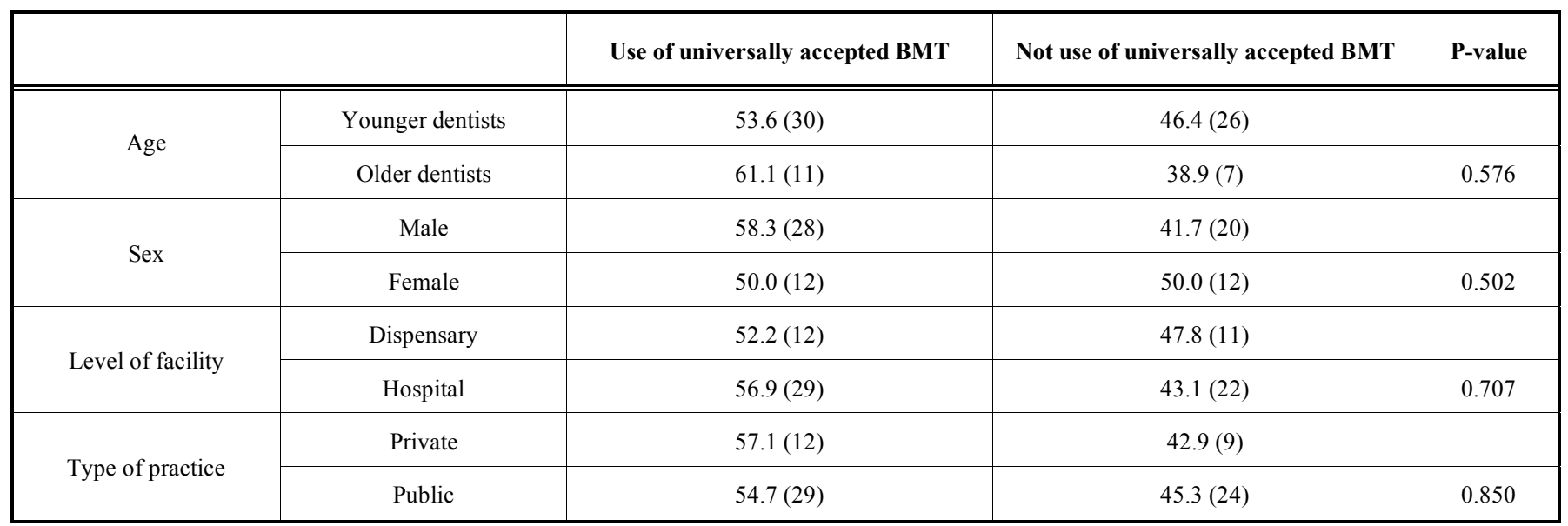

Table 5. Distribution of practitioners' awareness on universally applied BMTs when handling child dental patients by experiences and training.

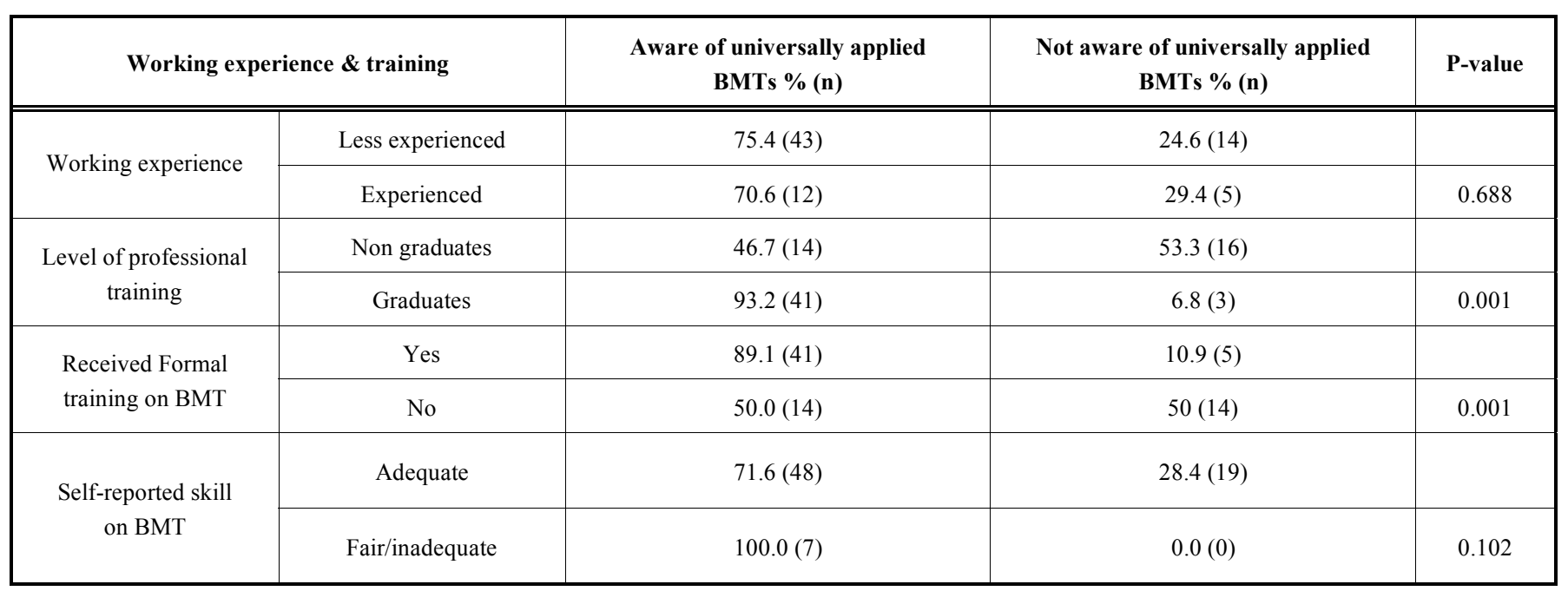


Table 6. Distribution the dental practitioners' use of universally applied BMTs when handling child dental patients by working experiences and training.

\begin{tabular}{|c|c|c|c|c|}
\hline \multicolumn{2}{|c|}{ Working experience \& training } & \multirow{2}{*}{$\begin{array}{c}\text { Use of universally applied BMTs } \\
\% \text { (n) }\end{array}$} & \multirow{2}{*}{$\begin{array}{c}\text { Do not use of universally applied } \\
\text { BMTs \% (n) } \\
47.4(27)\end{array}$} & \multirow[t]{2}{*}{ P-value } \\
\hline Wollin & Less experienced & & & \\
\hline & Experienced & $64.7(11)$ & $35.3(6)$ & 0.379 \\
\hline $\begin{array}{l}\text { Level of professional } \\
\text { training }\end{array}$ & Non-graduate & $46.7(14)$ & $53.3(16)$ & \\
\hline \multirow{2}{*}{$\begin{array}{l}\text { Received Formal } \\
\text { training on BMT }\end{array}$} & Yes & $58.7(27)$ & $41.3(19)$ & \\
\hline & No & $50.0(14)$ & $50.0(14)$ & 0.465 \\
\hline $\begin{array}{l}\text { Self-reported skill } \\
\quad \text { on BMT }\end{array}$ & Adequate & $50.7(34)$ & $49.3(33)$ & \\
\hline
\end{tabular}

Only few practitioners $7(9.5 \%)$ reported to have adequate skills to handle children, all of them were graduates. Most practitioners both graduates 37 (50\%) and Nongraduate $26(35.1 \%)$ reported to have fair skills. While none of the graduates rated themselves to have inadequate skills, 4 (5.4\%) Non-graduate did.

All practitioners who participated in the current study reported to be influenced by a child's past dental experience in the selection of a BMT during handling of a particular child. Parents' social economic status was reported by $17.6 \%$ of the practitioners to influence their choice of a behavior management technique. Generally, the child factors were reported by more practitioners than parents' factors to influence their choice for a BMT to be applied (Table 7).

Table 7. Factors influencing the choice of particular BMTs while handling a child dental patient.

\begin{tabular}{|c|c|}
\hline Influencing factors & \% (n) \\
\hline \hline Child's past dental experience & $100(74)$ \\
\hline Child's presenting condition & $97.3(72)$ \\
\hline Child's emotional state & $94.6(70)$ \\
\hline Child's social background & $89.2(66)$ \\
\hline Child's medical status & $87.8(65)$ \\
\hline Child's age & $82.4(61)$ \\
\hline Parent's fear/ anxiety state & $62.2(46)$ \\
\hline Personal condition on that day & $44.6(33)$ \\
\hline Parent's preference & $27(20)$ \\
\hline Parent's SES & $17.6(13)$ \\
\hline
\end{tabular}

\section{DISCUSSION}

Interpretation of the current findings should take in account that data were collected through interviews with oral health practitioners (participants). This might have overestimated the proportion of practitioners' awareness and application of behavior management techniques. Observation of the practitioners as they attended child dental patients and recording BMTs being used would have been much more appropriate data collection method thus it is recommended for future studies.

Generally, the results of the current study shows that dental practitioners' awareness on behavior management techniques is high which is a good and encouraging finding for the quality of oral health care of Tanzanian children. Practitioners' awareness on individual BMTs varied, the highest being for tell-show-do (100\%) a technique which is simple and probably easy to be remembered and lowest for hand over mouth technique $(29.7 \%)$ which is not universally applied in the country thus possibly often forgotten.

Practitioners' awareness on BMTs differed by age, sex, facility profile, working experiences and training. Younger and less experienced practitioners were aware of BMTs than their older colleagues, an observation that may be explained by positive changes in training curriculum that might have happened over time. Males were more aware of BMTs probably because in the African settings they are culturally less attached and involved with children than females; therefore during training they may pay more attention on issues pertaining to handling children as a measure for catching-up.

Unexpectedly, practitioners working at dental facilities placed to dispensary/health centre were more aware of the BMTs than those working at facilities located at hospitals. This was contrary to our expectations because practitioners working at dispensaries or health centres are mainly dental therapists or assistant dental officers who do not receive clinical training in paediatric dentistry. Moreover, those who were working in public dental facilities were found to be aware of the techniques than their counterparts. This could be explained by the fact that, a large proportion of participants in the current study was from a university teaching hospital which is the only facility with a paediatric dental clinic in the country and hence more likely to be applying 
the BMTs accordingly. Graduate participants and those reporting formal training were aware of the techniques than their counterparts, which is a likely outcome of the education received during their graduate course.

Very few participants of this study all of them being graduates self-report to have adequate skills in using BMT when managing child dental patients. This is contrary to Oredugba and Sanu [9] who reported $46.9 \%$ of the dentist to rate their undergraduate training in behavior management as adequate and $64.3 \%$ rating their skills to manage difficult behavior as fair. On the other hand, none of the graduates reported to have inadequate skills. This implies that undergraduate training on BMTs may not be sufficient to everyone as stated by Strøm et al. [16] that postgraduate courses has a strong relationship with dentists' use of BMT. Likewise Saudi paediatric dentists reported to use more specialized BMTs as compared to general dentists [17]. Furthermore, non-graduates in Tanzania do not get clinical training in Paediatric dentistry.

A substantial proportion of participants reported to use BMT, an observation which augments the findings on awareness on BMTs and likelihood of quality services provided to paediatric dental patients in Tanzania. Similarly, a study conducted by Ajlouni et al. [18] among Jordanian paediatric dentists reported that $85 \%$ of them always used behavior management techniques. In the current study, more older and experienced practitioners reported to use BMTs which implies the contribution of familiarity of working with children on using the techniques. Our findings are contrary to those of Wright et al. [13] who reported that younger dentists tended to use behavioral strategies more frequently than older ones. However, with specific techniques, Carr et al. [8], reported that the younger dentists (under the age of 30 years) were more likely to respond that they "never use" hand-over-mouth-with-airway restriction (HOMAR) than did older dentists, especially the over 50 years age group.

Male participants were found to use the BMTs more than females perhaps because males are naturally technical. This is contrary to the findings by Wright et al. [13] and Adair [11] who found significant sex differences, female dentists using certain techniques more often than males. Whereas, Wells et al. [19] reported no significant gender differences in the use of behavior guidance techniques among practitioners

The fact that more graduates and practitioners reporting to have received formal training used BMTs can be elucidated by the function of education received. This was earlier on reported by Folayan and Idehen in Nigeria [10] who stated that training has a role to play in the basic and efficient use in the management of the child dental patient.

An observation that more participants working at facilities located at hospitals used BMTs may have resulted from a large proportion of participants in this study to be working at a hospital facility hosting the only paediatric dental clinic where every practitioner treat children thereby facilitating use of BMTs. A difference in use of BMTs among dentists practicing at diverge facilities was reported by Carr et al. [8], that more dentists in sub-urban areas never used the papoose board than did dentists in rural or urban areas.
More practitioners working at private facilities used BMTs. Similar to Juntgen [20] who reported type of practice to influence utilization of behavior guidance techniques. The nature of private dental facilities in Tanzania may lead to fewer, possibly informed and demanding parents to visit these clinics. Consequently practitioners may have enough time to allocate to handling children and may have to conform to what parents' demands.

Largely, children's factors influenced practitioners' choice of BMT to be used in a particular child patient. This indicates that the child's nature and presenting behavior in the dental settings is important. Of the child's factors, previous dental experience was reported by majority to influence their choice which underscores the importance of proper child handling in paediatric dentistry. Similar findings were reported by Oredugba and Sanu [9] who informed that the major factors influencing choice of behavior management technique was child's age. Unlike our findings, Carr et al. [8] reported the reasons for changes in the utilization pattern for most behavior management techniques to be parental influences.

\section{CONCLUSION}

Most participants were aware of BMTs, although few acknowledged having adequate skills to apply the techniques. They use BMTs during treatment of paediatric dental patients and their choice of the technique is mainly influenced by children's factors.

\section{RECOMMENDATION}

Continuing education is needed to provide dental practitioners with skills to apply BMT during handling of paediatric dental patients.

\section{LIST OF ABBREVIATIONS}

$\begin{array}{ll}\text { ADO } & =\text { Assistant Dental Officer } \\ \text { BDS } & =\text { Bachelor of Dental Science } \\ \text { BMTs } & =\text { Behavior Management Techniques } \\ \text { DDS } & =\text { Doctor of Dental Surgery } \\ \text { DT } & =\text { Dental Therapist } \\ \text { HOMAR } & =\text { Hand-Over-Mouth-With-Airway Restriction } \\ \text { SES } & =\text { Social Economic Status } \\ \text { SPSS } & =\text { Statistical Package for Social Sciences }\end{array}$

\section{CONFLICT OF INTEREST}

The authors confirm that this article content has no conflict of interest.

\section{ACKNOWLEDGEMENTS}

We thank all study participants for their time and cooperation and the Tanzanian Government through Ministry of Health \& Social Welfare for the financial support.

\section{REFERENCES}

[1] Roberts JF, Curzon MEJ, Koch G, Martens LC. Review: behavior management techniques in paediatric dentistry. Eur Arch Paediatr Dent 2010; 11: 166-74. 
[2] Pinkham JR. Behavioral themes in dentistry for children: 19681990. ASDC J Dent Child 57: 38-45.

[3] Oliver K, Manton D. Contemporary behavior management techniques in clinical pediatric dentistry: out with the old and in with the new? J Dent Child 2015; 82(1): 22-8.

[4] Crossley ML, Joshi G. An investigation of paediatric dentists attitude towards parental accompaniment and behavioural management techniques in the UK. Br Dent J 2002; 192: 517-21.

[5] American Academy on Pediatric Dentistry Clinical Affairs Committee-Behavior Management Subcommittee; American Academy on Pediatric Dentistry Council on Clinical Affairs. Guideline on behavior guidance for the pediatric dental patient. Pediatr Dent $\mathrm{J}$ 2015; 30: 125-33.

[6] Rogers CR. A theory of therapy, personality, and interpersonal realtionships, as developed in the client-centered framework. Psychology: A Study of a Science, Formulations of the Person and the Social Context, In: Koch S, ed. New York: McGraw-Hill, 1959; p. 199.

[7] Strange D. The evolution of behavior guidance: a history of professional, practice, corporate and societal influences. Pediatr Dent 2014; 36(2): 128-31.

[8] Carr K, Wilson S, Nimer S, Thornton J. Behavior management techniques among pediatric dentists practicing in the southeastern United States. Pediatr Dent 1999; 21(6): 347-53.

[9] Oredugba FA, Sanu OO. Behavior Management Techniques Employed by Nigerian Dentists for their Child Patients. Pesqui Bras Odontopediatria Clin Integr 2009; 9: 271-6.

[10] Folayan MO, Idehen E. Factors influencing the use of behavioral management techniques during child management by dentists. J Clin Pediatr Dent 2004; 28: 155-61.
[11] Adair S, Schafer T. Age and gender differences in the use of behavior management techniques by pediatric dentists. Pediatrics 2007; 29(5): 403-8.

[12] Peretz B, Glaicher H, Ram D. Child-management techniques. Are there differences in the way female and male pediatric dentists in Israel practice? Braz Dent J 2003; 14: 82-6.

[13] Wright FA, Giebartowski JE, McMurray NE. A national survey of dentists' management of children with anxiety or behavior problems. Aust Dent J 1991; 36: 378-83.

[14] Sharath A, Rekka P, Muthu MS, Rathna Prabhu V, Sivakumar N. Children's behavior pattern and behavior management techniques used in a structured postgraduate dental program. J Indian Soc Pedod Prev Dent 2009; 27: 22-6.

[15] Grewal N. Implementation of behavior management techniques: how well accepted they are today. J Indian Soc Pedod Prev Dent 2003; $21: 70-4$

[16] Strøm K, Rønneberg A, Skaare AB, Espelid I, Willumsen T. Dentists' use of behavioural management techniques and their attitudes towards treating paediatric patients with dental anxiety. Eur Arch Paediatr Dent 2015; 16(4): 349-55.

[17] Abushal M, Adenubi J. The use of behavior management techniques by dentists in Saudi Arabia: a survey. Saudi Dent J 2000; 12(3): 129-34.

[18] Ajlouni O, Al-Moherat F, Habahbeh R. Behavior Management Techniques among Jordanian Pediatrics Dentists. J RMed Serv.

[19] Wells M, McTigue DJ, Casamassimo PS, Adair S. Gender shifts and effects on behavior guidance. Pediatr Dent 2015; 36: 138-44.

[20] Juntgen L, Sanders B. Factors influencing behavior guidance: a survey of practicing pediatric dentists. Pediatrics 2013; 35(7): 53945 .

\footnotetext{
Received: April 09, 2015

(C) Kawia et al.; Licensee Bentham Open.
}

Revised: September 30, 2015

Accepted: October 31, 2015

This is an open access articles licensed under the terms of the Creative Commons Attribution-Non-Commercial 4.0 International Public License (CC BY-NC 4.0) (https://creativecommons.org/licenses/by-nc/4.0/legalcode), which permits unrestricted, non-commercial use, distribution and reproduction in any medium, provided that the work is properly cited. 